\title{
A Randomized Encouragement Trial to Increase Mail Order Pharmacy Use and Medication Adherence in Patients with Diabetes
}

\author{
Bharathi Ramachandran, MPH' , Connie M. Trinacty, PhD², J. Frank Wharam, MD ${ }^{3}$, \\ O Kenrik Duru, MD', Wendy T. Dyer, MS ${ }^{5}$, Romain S. Neugebauer, $P h D^{5}$, \\ Andrew J. Karter, $P h D^{5}$, susan D. Brown, $P h D^{5,6}$, Cassondra J. Marshall, DrPH, MPH', \\ Deanne Wiley, $B A^{5}$, Dennis Ross-Degnan, $S C D^{3}$, and Julie A. Schmittdiel, $P h D^{5}$ (D)
}

${ }^{1}$ Cohere Health, Boston, MA, USA; ${ }^{2}$ University of Hawail at Manoa, Honolulu, HI, USA; ${ }^{3}$ Harvard Medical School and Harvard Pilgrim Health Care Institute, Boston, MA, USA; ${ }^{4}$ University of California, Los Angeles, Los Angeles, CA, USA; ${ }^{5}$ Division of Research, Kaiser Permanente Northern California, Oakland, CA, USA; ${ }^{6}$ School of Medicine, University of California, Davis, Sacramento, CA, USA; 7 University of California, Berkeley, Berkeley, CA, USA.

BACKGROUND: Mail order pharmacy (MOP) use has been linked to improved medication adherence and health outcomes among patients with diabetes. However, no largescale intervention studies have assessed the effect of encouraging MOP use on medication adherence.

OBJECTIVE: To assess an intervention to encourage MOP services to increase its use and medication adherence.

DESIGN: Randomized encouragement trial.

PATIENTS: 63,012 diabetes patients from three health care systems: Kaiser Permanente Northern California (KPNC), Kaiser Permanente Hawaii (KPHI), and Harvard Pilgrim Health Care (HPHC) who were poorly adherent to at least one class of cardiometabolic medications and had not used MOP in the prior 12 months.

INTERVENTION: Patients were randomized to receive either usual care (control arm) or outreach encouraging MOP use consisting of a mailed letter, secure email message, and automated telephone call outlining the potential benefits of MOP use (intervention arm). HPHC intervention patients received the letter only.

MEASUREMENTS: We compared the percentages of patients that began using MOP and that became adherent to cardiometabolic medication classes during a 12-month follow-up period. We also conducted a race/ethnicitystratified analysis.

RESULTS: During follow-up, $10.6 \%$ of intervention patients began using MOP vs. $9.3 \%$ of controls $(p<0.01)$; the percent of cardiometabolic medication delivered via mail was $42.1 \%$ vs. $39.8 \%$ ( $p<0.01)$. Metformin adherence improved in the intervention arm relative to control at the two KP sites ( $52 \%$ vs. $49 \%, p<0.01)$. Stratified analyses suggested a significant positive effect of the intervention in White (RR: 1.12, 95\% CI: 1.03, 1.22) and Asian (RR: 1.30, 95\% CI: $1.17,1.45)$ patients.

CONCLUSION: This pragmatic trial showed that simple outreach to encourage MOP modestly increased its use and improved adherence measured by refills to a key class of diabetes medications in some settings. Given its minimal cost, clinicians and health systems should consider

Received March 31, 2020

Accepted September 10, 2020

Published online October 1, 2020 outreach interventions to actively promote MOP use among diabetes patients.

TRIAL REGISTRATION: ClinicalTrials.gov registration number: NCT02621476

KEY WORDS: diabetes; mail order pharmacy; medication adherence; encouragement trial.

\section{Abbreviations \\ SES \\ $\mathrm{KP}$ \\ KPNC \\ $\mathrm{KPHI}$ \\ $\mathrm{HPHC}$ \\ PDC \\ IVR \\ CVD \\ J Gen Intern Med 36(1):154-61 \\ DOI: $10.1007 / \mathrm{s} 11606-020-06237-8$ \\ (C) Society of General Internal Medicine 2020}

socioeconomic status

Kaiser Permanente

Kaiser Permanente Northern California Kaiser Permanente Hawaii

Harvard Pilgrim Health Care proportion of days covered automated phone call cardiovascular disease

\section{INTRODUCTION}

Diabetes is the seventh leading cause of death in the USA and affects over 34 million Americans. ${ }^{1,2}$ The prevalence of diabetes is projected to continually increase through $2060 .^{3}$ While diabetes complication rates may be decreasing among older patients, the rise in diabetes prevalence continues to cause significant diabetes-related complications in younger and middle-aged patients and costs the US health care system up to $\$ 176$ billion annually. ${ }^{4,5}$

Poor medication adherence is prevalent among patients with diabetes, and non-adherence is associated with poor risk factor control and adverse health outcomes. ${ }^{6-9}$ Adherence to glucose-lowering medications is associated with improved glycemic control, fewer hospitalizations, and lower mortality. ${ }^{10}$ However, only $50-70 \%$ of patients with chronic conditions are adherent to their medications. ${ }^{11-13}$ Minorities and low socioeconomic status (SES) patients with diabetes have 
poorer medication adherence than Whites and higher-SES diabetes patients. ${ }^{14-19}$

Hundreds of interventions have been evaluated and published in efforts to improve medication adherence over the last 60 years. ${ }^{11,20,21}$ Many of these interventions require substantial investments of personnel, time, and financial resources, and the vast majority achieve only modest improvements in adherence, which often dissipate once the intervention phase concludes. ${ }^{22}$

Research suggests that mail order pharmacy (MOP) use may be a sustainable approach to improving medication adherence among patients with chronic conditions. Retrospective and cross-sectional studies using observational data have established a link between MOP use and greater adherence in patients with diabetes. ${ }^{23-28}$ Numerous studies also suggest that MOP use is potentially cost-saving to both patients and health plans. ${ }^{29,30}$ In addition, for patients who are at high risk for infection, recently issued CDC guidelines recommend MOP use to reduce risk and to continue medication adherence. ${ }^{31}$ Despite this evidence, fewer than $25 \%$ of patients with diabetes use MOP to obtain their diabetes medications and use is even lower among non-Whites and patients with lower socioeconomic status. ${ }^{23,32}$

Qualitative evidence suggests that the lack of knowledge about the process of MOP enrollment and medication ordering is a major access obstacle for many potential users. ${ }^{33}$ There is currently little to no published evidence of successful patientdirected interventions that promote MOP use to increase its use and assess its impact on medication adherence. Therefore, we e conducted a multi-site, randomized, pragmatic trial in 3 health care systems: Kaiser Permanente Northern California (KPNC) and Hawaii (KPHI), and Harvard Pilgrim Health Care (HPHC) to address the research question of whether encouraging the use of MOP among diabetes patients with poor adherence to cardiovascular disease (CVD) risk factor medications would increase the use of MOP and improve medication adherence. We hypothesized that both MOP use and adherence would improve in the intervention group relative to the control group and that the intervention would not negatively impact health care disparities.

\section{METHODS}

\section{Study Setting and Population}

This pragmatic trial was embedded within three health care systems that represent geographic, demographic, and structural diversity; together, they serve over 6 million health plan members. KPNC is a non-profit, integrated, group-model health care delivery system that serves more than 4 million members in a 13-county area of Northern California. This population is more than $30 \%$ non-White, $20 \%$ have a high school or lower level of education, and almost $50 \%$ have a household income $<\$ 50 \mathrm{~K}$ annually. KPHI is a non-profit, mixed-model health maintenance organization that serves more than 250,000 members throughout Hawaii. This population is $70 \%$ non-White, representing one of the most ethnically and racially diverse populations in the USA; $16 \%$ have attained a high school or lower level of education, and about $45 \%$ have a household income $<\$ 50 \mathrm{~K}$ annually. HPHC is the oldest non-profit, managed health care organization and currently insures more than 1.3 million members in New England who receive care in a variety of organizational settings. Membership includes both urban and rural populations and is about $20 \%$ non-White and about $35 \%$ live in low income or low education neighborhoods.

\section{Mail Order Pharmacy Within the Health Care Systems}

KPNC and KPHI maintain a MOP distribution system, with free shipping, in coordination with more than 120 local walkin pharmacies located within KP outpatient clinics and hospitals. Although most new prescriptions are filled in a local KP pharmacy, members can elect to receive their prescription refills via MOP, ordered either through the secure online patient portal (kp.org) or a toll-free pharmacy refill telephone service, using a credit card. KP members have telephone access to a pharmacist to answer medication-related questions regardless of how a refill was dispensed. There is no minimum days' supply required for MOP. KP typically dispenses 90 100-day medication supplies through both MOP and local KP pharmacies. Some members have a financial incentive to use MOP as part of their pharmacy benefits where they pay one copayment for a 30-day supply at their local pharmacy or 2 copayments for a 90-100-day supply if they refill their medications via $\mathrm{MOP}^{32}$

HPHC has a MOP program, with free shipping, which allows members to receive delivery of a 90-day supply of maintenance medications to their home. Members can request a new order or refill their prescriptions either online through HPHC's secure website, by phone (requiring their HPHC member ID number, prescription number(s), and credit card information), or complete a service form to be mailed to Walgreens, which served as HPHC's mail order service provider at the time of the study.

\section{Study Participants}

Study participants were identified using electronic health record data at KPNC and KPHI and using insurance claims data at HPHC. Study eligibility was determined during a baseline period from January 6, 2016, to January 5, 2017, at both KP sites and from October 1, 2015, to September 30, 2016, at HPHC, due to data availability. Patients were considered eligible if they had (a) at least 1 primary inpatient diagnosis or 2 outpatient diagnoses of type 2 diabetes or had dispensing of a diabetes drug; (b) were at least 18 or older; (c) were nonadherent (proportion of days covered $(\mathrm{PDC})<80 \%$ ) to at least one oral CVD drug class which includes diabetes, blood pressure, and lipid-lowering drugs; and (d) had not used 
MOP to fill oral CVD medications in the previous 12 months. Participants were required to have active health plan membership in the past 12 months. We excluded patients with a pregnancy-related diagnosis or a diagnosis of dementia or traumatic brain injury in the prior 12 months. At both KP sites, further exclusions included patients who were hospitalized, residing in a skilled nursing facility, or participating in hospice or home health when eligible patients were identified for the study.

\section{Study Design and Implementation}

We employed a randomized trial design (ClinicalTrials.gov registration number NCT02621476) to encourage mail order pharmacy use in which we randomly assigned patients to one of 2 arms: a control arm which received usual care or an intervention arm which received outreach encouraging MOP use (Fig. 1). We used the "surveyselect" procedure in SAS v9.4 to randomize half of the eligible patients to the intervention arm and half to the control arm. Patients, pharmacists, and providers were blinded to randomization arm, while researchers were aware of randomization arm. The intervention outreach consisted of a mailed letter, secure email message, and/or automated telephone call (IVR) that outlined the potential benefits of MOP use for diabetes patients. HPHC patients in the intervention arm received the letter only because telephone and email outreach to members is limited in this system. Only KP participants with active KP.org accounts (48\%) received a secure email message. The outreach materials were developed based on formative research conducted with patient members who identified key information that was worth noting such as the availability and benefits of MOP services within the patient's health plan, how to enroll and order medications, and how patients could access the existing pharmacy support services, so that any additional questions on the MOP services or their individual medications could be addressed by a qualified health professional. ${ }^{33}$ The first outreach - the mailed letter - was mailed on February 21,

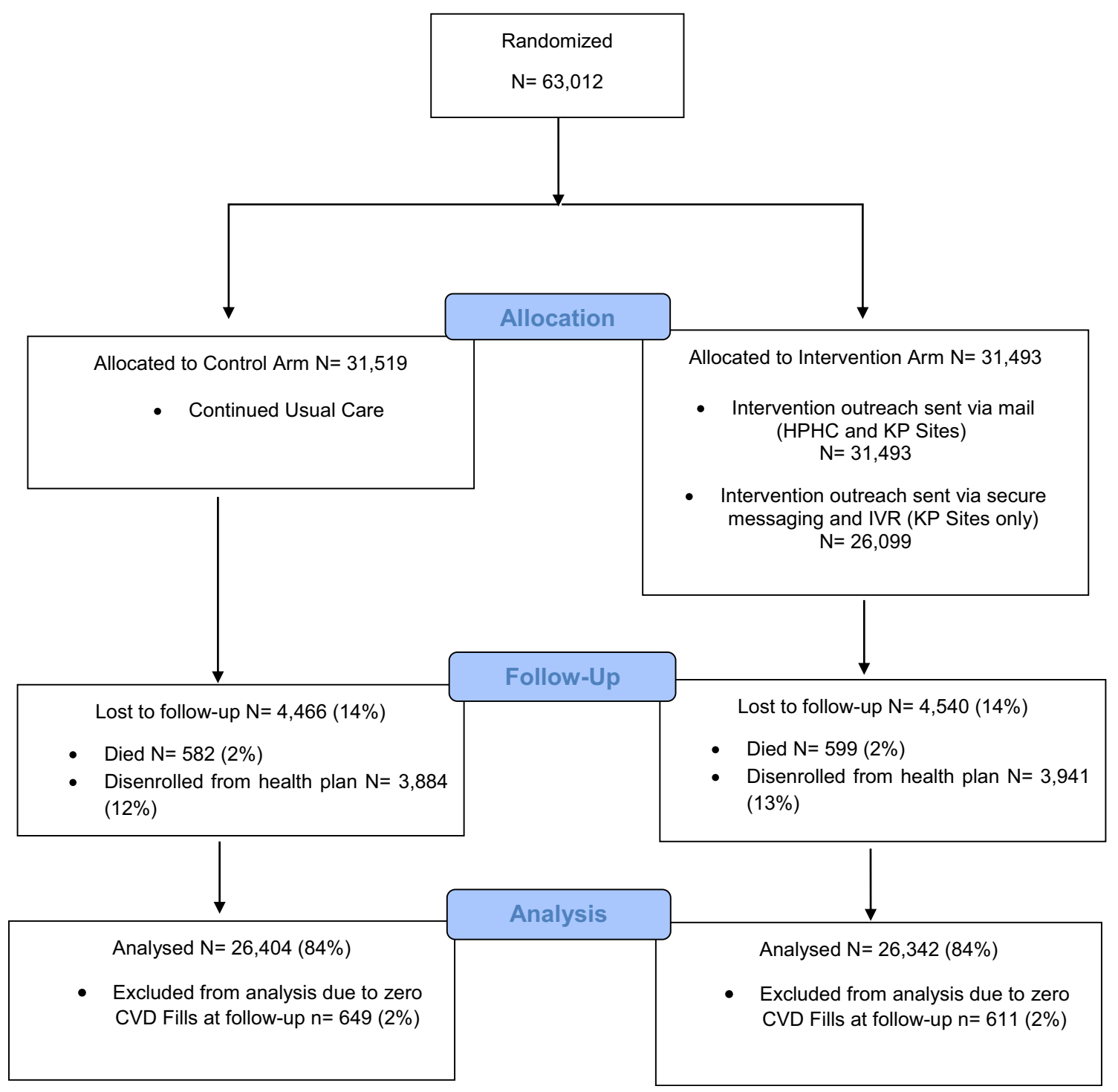

Figure 1 Flow chart of recruitment, arm assignment, and follow-up of participants in the EMPOWER Study, across all sites. 
2017, at KPNC and the following day at KPHI and HPHC. The secure email message was completed 2 weeks after the mailed letter at KPNC and 2 months after at KPHI. The last outreach using the IVR telephone call was completed 2 weeks following the secure email message at both KP sites. Outreach was completed at all KP sites on May 9, 2017, and on February 22, 2017, at HPHC. Patients were followed for 12 months from the date of the mailed letter. The last day of follow-up was February 20, 2018. The cost of delivering the intervention outreach included printing and mailing letters, programming and recording the message for the IVR phone calls, and programming secure email messages. Cost figures for the outreach letters came from invoices received from vendors hired to print and mail the letters. We also received a bill for the costs of programming the IVR for the phone calls. Programming the secure email messages took an estimated $20 \mathrm{~h}$. Using the middle of the salary range for a support staff member at the time of the outreach, including benefits and indirect costs, we estimated the hourly labor cost to be $\$ 64.79$; secure message costs were calculated using this approximation. In sum, the total estimated cost of intervention outreach was $\$ 16,667.47$ ( $\$ 0.53$ per patient).

\section{Study Outcomes}

Patients were considered to use MOP if they filled a CVD drug at least once via the MOP system during the follow-up period. We calculated adherence to each oral CVD drug class using the PDC method and defined non-adherence as having a PDC $<80 \%{ }^{34}$

\section{Statistical Analysis}

To examine the relationship of encouraging MOP use with MOP use and adherence, we estimated the differences in MOP use and CVD medication adherence at follow-up between the two arms using chi-square tests in an intent-to-treat (ITT) analysis. Differences in the percentages of CVD drug fills delivered by mail were estimated using $T$ test. To determine whether MOP use differed by race/ethnicity, we calculated risk ratios using modified Poisson regression comparing the effect of treatment on outcomes within each group. We used chi-square tests to compare the percent of patients with a hospitalization or emergency department visit during follow-up between the intervention and control arm and compared the number of primary care visits between arms using the Kruskal-Wallis test. Patients who died or who disenrolled from their health plan during follow-up were excluded from the analysis. In addition, those who did not have a CVD medication fill during the follow-up period were also excluded since we were unable to assess whether they used MOP. Sensitivity analysis was conducted to assess the impact of those without CVD medication fills during follow-up by including them in the analytic population as non-users of MOP at follow-up. All analyses were further stratified by site and results from both the KP sites were collapsed based on the similarity of study results in the two sites, and because their pharmacy distribution structure and health care systems were also similar in comparison with HPHC. All analyses were performed using SAS (version 9.4, Cary, NC).

\section{RESULTS}

We randomized a total of 63,012 patients across all three sites. At baseline, the study sample was more than half male (55\%) and had an average age of 60 years. Twenty-four percent were non-Hispanic White, $12 \%$ were Black, 25\% were Hispanic, $18 \%$ were Asian, and $4 \%$ were Native Hawaiian/Pacific Islander. Almost two-thirds (64\%) had a financial incentive to use MOP. On average, study participants were on 3.5 oral CVD drug classes and non-adherent to more than half of them (58\%). Baseline demographic and clinical characteristics were not significantly different between arms (Table 1).

After excluding those who died (1181), disenrolled (7825), or had zero CVD drug fills (1260) during follow-up, 52,746 $(84 \%)$ patients remained for the analysis and $5254(10 \%)$ of these patients used MOP to refill their oral CVD drugs during follow-up. There were significant differences between arms at follow-up in both the use of MOP to refill oral CVD drugs and the percentage of CVD drugs refilled by mail (Table 2). A higher percentage of patients in the intervention arm used MOP to refill their oral CVD drugs compared with those in the control arm $(10.6 \%$ vs $9.3 \%, p<0.01)$. Although this positive effect was not seen at the HPHC site, which had a less intense outreach, the KP subsample saw an increased effect $(12.0 \%$ vs $10.5 \%, p<0.01)$.

Patients in the intervention arm also had a significantly greater mean percentage of CVD drug fills delivered by mail than the control arm $(42.1 \%$ vs $39.8 \%, p<0.01)$. This positive effect was seen in the KP subsample $(42.0 \%$ vs $39.7 \%$, $p<0.01$ ) but was not statistically significant at the HPHC site. In our sensitivity analysis, we tested the impact of including patients who had zero CVD drug fills during follow-up in our analytic sample, on the MOP outcome. The results revealed comparable positive effects of the intervention on MOP use and the mean percentage of CVD drug fills delivered by mail. These differences between the study arms did not differ when examined by quarter (data not shown.)

Among patients who were non-adherent to metformin at baseline $(n=14,368)$, more than half became adherent to this medication during follow-up, $55 \%$ in the intervention arm, and $54 \%$ in the control arm $(p=0.09)$. The between-arm difference was statistically significant at the KP sites only ( $52 \%$ vs $49 \%$, $p=0.02$; Table 3). Adherence to the other CVD drug classes was also analyzed, but we found no significant differences by arm during follow-up. 
Table 1 Baseline Characteristics of Study Participants by Study Arm at Kaiser Permanente Northern California (KPNC), Kaiser Permanente Hawaii (KPHI), and Harvard Pilgrim Health Care (HPHC)

\begin{tabular}{|c|c|c|c|c|}
\hline & Total, \%, Mean [SD] & Control, \%, Mean [SD] & Intervention, \%, Mean [SD] & \\
\hline KPNC & 48,339 & 24,169 & 24,170 & \\
\hline KPHI & 3885 & 1956 & 1929 & \\
\hline HPHC & 10,788 & 5394 & 5394 & \\
\hline Total & 63,012 & 31,519 & 31,493 & \\
\hline Characteristics & & & & $p$ value \\
\hline Female & $45 \%$ & $45 \%$ & $45 \%$ & 0.40 \\
\hline Age & $60[12]$ & $60[12]$ & $60[12]$ & 0.34 \\
\hline$<20$ & $0.05 \%$ & $0.05 \%$ & $0.04 \%$ & 0.85 \\
\hline $20-29$ & $<1 \%$ & $<1 \%$ & $<1 \%$ & \\
\hline $30-39$ & $4 \%$ & $4 \%$ & $4 \%$ & \\
\hline $40-49$ & $14 \%$ & $15 \%$ & $14 \%$ & \\
\hline $50-59$ & $30 \%$ & $30 \%$ & $29 \%$ & \\
\hline $60-69$ & $29 \%$ & $29 \%$ & $29 \%$ & \\
\hline $70-79$ & $16 \%$ & $16 \%$ & $16 \%$ & \\
\hline $80-89$ & $6 \%$ & $6 \%$ & $6 \%$ & \\
\hline$>89$ & $1 \%$ & $1 \%$ & $1 \%$ & \\
\hline Race & & & & 0.14 \\
\hline Hispanic & $25 \%$ & $25 \%$ & $25 \%$ & \\
\hline Black & $12 \%$ & $12 \%$ & $12 \%$ & \\
\hline Hawaiian/Pacific Islander & $4 \%$ & $4 \%$ & $4 \%$ & \\
\hline Asian & $18 \%$ & $18 \%$ & $19 \%$ & \\
\hline Native American & $<1 \%$ & $<1 \%$ & $<1 \%$ & \\
\hline White & $24 \%$ & $25 \%$ & $24 \%$ & \\
\hline Missing & $16 \%$ & $16 \%$ & $16 \%$ & \\
\hline Has secure messaging * & $48 \%$ & $48 \%$ & $48 \%$ & 0.41 \\
\hline Has mail order incentive & $64 \%$ & $64 \%$ & $65 \%$ & 0.06 \\
\hline Had oral DM drug fill & $81 \%$ & $81 \%$ & $81 \%$ & 0.86 \\
\hline Had oral DL drug fill & $82 \%$ & $82 \%$ & $82 \%$ & 0.25 \\
\hline Had oral HT drug fill & $85 \%$ & $85 \%$ & $85 \%$ & 0.49 \\
\hline Total Number of Oral CVD Drug Fills & $13.5[10.2]$ & $13.5[10.2]$ & $13.5[10.2]$ & 0.12 \\
\hline Total Number of Oral HT Drug Fills & $7.4[6.5]$ & $7.4[6.5]$ & $7.3[6.4]$ & 0.12 \\
\hline Total Number of Oral DL Drug Fills & $3.6[2.7]$ & $3.6[2.7]$ & $3.6[2.7]$ & 0.37 \\
\hline Total Number of Oral DM Drug Fills & $5.3[4.2]$ & $5.3[4.1]$ & $5.3[4.2]$ & 0.12 \\
\hline \# of classes of Oral CVD Drugs & $3.5[1.6]$ & $3.5[1.6]$ & $3.5[1.6]$ & 0.82 \\
\hline \# of drug classes poorly adherent to & $1.7[1.0]$ & $1.7[1.0]$ & $1.7[1.0]$ & 0.96 \\
\hline$\%$ of oral CVD drug classes poorly adherent to & $57.6[31]$ & $57.6[31]$ & $57.6[31]$ & 0.91 \\
\hline Diabetes identification & & & & 0.10 \\
\hline One inpatient diagnosis & $<1 \%$ & $<1 \%$ & $<1 \%$ & \\
\hline One prescription fill & $50 \%$ & $50 \%$ & $50 \%$ & \\
\hline Two outpatient diagnosis & $50 \%$ & $50 \%$ & $50 \%$ & \\
\hline
\end{tabular}

$*$ Denominator restricted to those who used MOP at FUP: KP sites $=5208 ;$ all sites $=5254$

To examine the differential effects of the intervention across racial/ethnic groups, we estimated the odds ratio comparing the effect of the intervention on the outcomes in each group (Table 4). All racial/ethnic groups showed a positive effect of the intervention in MOP use, although only the White and Asian race groups showed a statistically significant difference (RR: 1.12 (95\% CI: 1.03, 1.22) and RR 1.30 (95\% CI: 1.17, 1.45, respectively) and the Hispanics (RR: $1.10,95 \%$ CI: 0.98 , 1.23 ) showed a borderline significance. Only Whites showed a statistically significant difference in metformin adherence by arm in the KP subpopulation (RR: 1.10, 95\% CI: 1.03, 1.18). Medical utilization did not differ between the study and control arms in the follow-up period (data not shown).

\section{DISCUSSION}

Observational studies have shown positive associations between MOP use and medication adherence in diabetes patients, but qualitative evidence suggests that many patients encounter important barriers to using MOP due to lack of knowledge about how MOP works and the lack of technology literacy. ${ }^{33}$ Our study is the first randomized pragmatic trial to use simple, evidence-based outreach to address these barriers and encourage the use of existing mail order services to assess changes in medication adherence in diabetes patients.

The results indicate that those who received encouragement increased their use of MOP and had a greater percentage of CVD drug fills by mail than those receiving no active encouragement at all sites. A greater percentage of patients in the intervention arm also became adherent to metformin at both $\mathrm{KP}$ sites, but this difference was attenuated and was not statistically significant after including HPHC. This could be due to the difference in the number of outreach attempts between the KP sites and HPHC, where intervention patients only received mailed outreach once. Prior literature on patientfocused outreach suggests that email and telephone contacts can be as effective, or more effective, than traditional letter outreach. ${ }^{35}$ While the current study was not designed to directly compare the effectiveness of modes of outreach, our 
Table 2 Mail Order Pharmacy (MOP) Use and CVD Drug Fills by Study Arm

\begin{tabular}{|c|c|c|c|c|c|c|}
\hline \multicolumn{4}{|l|}{ KP sites } & \multicolumn{3}{|l|}{ All sites } \\
\hline Outcome & $\begin{array}{l}\text { Intervention \% }(95 \% \\
\text { CI) }\end{array}$ & $\begin{array}{l}\text { Control \% }(95 \% \\
\text { CI) }\end{array}$ & $\begin{array}{l}p \\
\text { value }\end{array}$ & $\begin{array}{l}\text { Intervention, \% (95\% } \\
\text { CI) }\end{array}$ & $\begin{array}{l}\text { Control, \% (95\% } \\
\text { CI) }\end{array}$ & $\begin{array}{l}p \\
\text { value }\end{array}$ \\
\hline MOP use & $12.0 \%(11.6,12.4)$ & $10.5 \%(10.1,10.9)$ & \multirow{2}{*}{$\begin{array}{l}< \\
0.001 \\
<0.01\end{array}$} & $10.6 \%(10.3,11.0)$ & $9.3 \%(8.9,9.7)$ & \multirow{2}{*}{$\begin{array}{l}< \\
0.001 \\
<0.01\end{array}$} \\
\hline $\begin{array}{l}\text { Mean percent of } \\
\text { CVD } \\
\text { drug fills using } \\
\text { MOP* }\end{array}$ & $42 \%(41.0,43.1)$ & $40 \%(38.6,40.9)$ & & $42 \%(41.1,43.2)$ & $40 \%(38.7,40.9)$ & \\
\hline
\end{tabular}

*Not available at HPHC

$D M$, diabetes mellitus; HT, hypertension; DL, dyslipidemia; CVD, cardiovascular disease

findings suggest that adherence interventions consider multimodal strategies that leverage electronic methods like IVR and secure messaging.

Our findings are consistent with prior observational research on the relationship between MOP and medication adherence, ${ }^{23-28}$ most recently a 4 -year study by Schwab et al. ${ }^{36}$ which found that adherence was greater for MOP patients compared with community pharmacy users at 12 months and this effect was sustainable through 48 months. This further suggests that encouraging MOP use can be a tool for improving long-term medication adherence. Compared with observational studies which found voluntary use of MOP compared to walk-in pharmacy was associated with an 8-percentage point improvement in adherence to antidiabetic medications, our findings suggest the adherence benefit is smaller. ${ }^{25}$ Although we only observed an increase in medication adherence in metformin, it is the most commonly used and first-line medication for diabetes. Similar improvements in medication adherence associated with MOP have also been found for other chronic conditions. ${ }^{24,28,37}$

There are several reasons why encouraging MOP use may be modestly associated with improved adherence. Qualitative research suggests that patients prefer aspects of MOP such as monetary incentives, ease of access, and greater convenience without waiting in long lines at the pharmacy. ${ }^{33,37,38}$ This qualitative evidence reinforces the findings in our study. The convenience of MOP use is also encouraged during pandemics and severe outbreaks in efforts to reduce risk among chroni- cally ill patients. $^{31}$

Subgroup analysis indicates that both the White and Asian race patients experienced improvements from the MOP encouragement intervention. Although the other race/ethnic groups did not show a statistically significant difference, the positive effect in the study arm is a promising indication towards our intervention efforts to address prior disparities. The underlying reasons for these disparities are multifactorial and include inability to afford prescribed medications, ${ }^{17,39,40}$ low health literacy and low health numeracy, ${ }^{41}$ low patient self-efficacy, ${ }^{42}$ and inadequate patient-provider communication. ${ }^{43,44}$ Although we tried to address some of these concerns in our intervention, future research, and methods to better address the more complex, overlapping barriers are warranted.

There are several limitations to our study. We measured adherence to medications for only the first 12 months after the intervention began, so our findings may not reflect long-term adherence changes or impact. We measured medication adherence based only on medication fills using the PDC method, which has not been validated specifically for MOP use. However, validation research has shown this method to be significantly associated with objective measures of actual medication consumption ${ }^{45}$, and our settings did not use mail order "auto-fills" to patients that might bias the results. We could not control for differences in health care providers and system characteristics which could influence medication adherence and MOP use. Our study included only non-MOP users among previously non-adherent patients; these patients may

Table 3 Adherence to CVD Drugs During Follow-up by Study Arm* ${ }^{*}$

\begin{tabular}{|c|c|c|c|c|c|c|}
\hline \multicolumn{4}{|l|}{ KP sites } & \multicolumn{3}{|l|}{ All sites } \\
\hline Drug class & $\begin{array}{l}\text { Intervention, \% }(95 \% \\
\text { CI) }\end{array}$ & $\begin{array}{l}\text { Control, \% (95\% } \\
\text { CI) }\end{array}$ & $\begin{array}{l}p \\
\text { value }\end{array}$ & $\begin{array}{l}\text { Intervention, \% }(95 \% \\
\text { CI) }\end{array}$ & $\begin{array}{l}\text { Control, \% (95\% } \\
\text { CI) }\end{array}$ & $\begin{array}{l}p \\
\text { value }\end{array}$ \\
\hline Metformin & $51.5 \%(50.2,52.8)$ & $49.5 \%(48.2,50.7)$ & 0.03 & $55.0 \%(5,3.856 .1)$ & $53.6 \%(52.4,54.7)$ & 0.09 \\
\hline Sulfonylureas & $51.1 \%(49.6,52.6)$ & $51.4 \%(49.9,52.8)$ & 0.83 & $52.7 \%(51.2,54.1)$ & $52.8 \%(51.4,54.2)$ & 0.90 \\
\hline Statins & $55.0 \%(53.8,56.1)$ & $55.5 \%(54.4,56.6)$ & 0.50 & $54 \%(53.0,55.1)$ & $54 \%(53.3,55.4)$ & 0.62 \\
\hline Ace inhibitors & $57.7 \%(56.0,59.4)$ & $56.4 \%(54.8,58.1)$ & 0.31 & $56.7 \%(55.1,58.3)$ & $56.2 \%(54.6,57.7)$ & 0.63 \\
\hline Beta blockers & $54.9 \%(52.8,56.9)$ & $53.4 \%(51.4 .55 .3)$ & 0.30 & $55.9 \%(54.0,57.7)$ & $54.5 \%(52.7,56.4)$ & 0.31 \\
\hline $\begin{array}{l}\text { Calcium channel } \\
\text { blockers }\end{array}$ & $59.4 \%(56.8,62.0)$ & $59.0 \%(56.4,61.6)$ & 0.83 & $59.5 \%(57.1,61.9)$ & $58.0 \%(55.6,60.4)$ & 0.38 \\
\hline ARBs & $63.8 \%(61.5,66.0)$ & $61.8 \%(59.5,64.0)$ & 0.23 & $62.3 \%(60.2,64.5)$ & $61.0 \%(58.9,63.2)$ & 0.40 \\
\hline Diuretics & $57.0 \%(55.0,59.0)$ & $57.3 \%(55.4,59.3)$ & 0.81 & $57.1 \%(55.3,58.9)$ & $56.5 \%(54.7,58.3)$ & 0.65 \\
\hline
\end{tabular}

*Denominator restricted to those who were non-adherent at baseline and had at least 2 metformin fills during follow-up (KP sites $=12,062 ;$ all sites $=14,368)$

Table includes the most commonly used drugs, with the power to detect differences 
Table 4 Mail Order Pharmacy Use and Metformin Adherence Stratified by Race/Ethnicity

\begin{tabular}{|c|c|c|c|c|c|c|c|c|}
\hline Outcome & & Hispanic & Black & $\begin{array}{l}\text { Hawaiian/Pacific } \\
\text { Islander }\end{array}$ & Asian & $\begin{array}{l}\text { Native } \\
\text { American }\end{array}$ & White & Missing \\
\hline $\begin{array}{l}\text { Mail order pharmacy use } \\
\text { Intervention vs control }\end{array}$ & $\begin{array}{l}\mathrm{KP} \\
\text { sites }\end{array}$ & $\begin{array}{l}1.10(0.99, \\
1.23)\end{array}$ & $\begin{array}{l}1.06(0.91, \\
1.23)\end{array}$ & $1.06(0.84,1.34)$ & $\begin{array}{l}1.30(1.17, \\
1.45)\end{array}$ & $\begin{array}{l}1.21(0.57 \\
2.54)\end{array}$ & $\begin{array}{l}1.12(1.03 \\
1.22)\end{array}$ & $\begin{array}{l}1.07(0.79, \\
1.47)\end{array}$ \\
\hline relative risk $(95 \% \mathrm{CI})$ & $\begin{array}{l}\text { All } \\
\text { sites }\end{array}$ & $\begin{array}{l}1.10(0.98, \\
1.23)\end{array}$ & $\begin{array}{l}1.07(0.92, \\
1.25)\end{array}$ & $1.06(0.84,1.33)$ & $\begin{array}{l}1.30(1.17, \\
1.45)\end{array}$ & $\begin{array}{l}1.18(0.56 \\
2.50)\end{array}$ & $\begin{array}{l}1.12(1.03, \\
1.22)\end{array}$ & $\begin{array}{l}1.07(0.80, \\
1.44)\end{array}$ \\
\hline $\begin{array}{l}\text { Metformin adherence } \\
\text { Intervention vs control } \\
\text { relative risk ( } 95 \% \mathrm{CI})\end{array}$ & $\begin{array}{l}\text { KP } \\
\text { sites }\end{array}$ & $\begin{array}{l}1.03(0.97, \\
1.10)\end{array}$ & $\begin{array}{l}1.01(0.89, \\
1.23)\end{array}$ & $1.04(0.87,1.24)$ & $\begin{array}{l}1.02(0.95, \\
1.09)\end{array}$ & $\begin{array}{l}1.01(0.67, \\
1.53)\end{array}$ & $\begin{array}{l}1.10(1.03 \\
1.18)\end{array}$ & $\begin{array}{l}1.03(0.85, \\
1.25)\end{array}$ \\
\hline
\end{tabular}

be less likely to adhere to therapy and harder to engage in MOP. It is possible that the evidence in favor of the intervention tested here is simply an artifact of contemporaneous system-level changes, since there was increased MOP use in the control group as well. However, to the best of our knowledge, there were no specific system-level changes that would have increased use of MOP services during the study period. While we employed a randomized controlled trial design, it is possible that there were underlying differences between the patients in the two study arms; however, our examination of patient characteristics in Table 1 suggests the two groups were similar. Our large sample size allowed us to detect relatively small clinical differences in MOP use and adherence between the arms and did not change medical utilization at follow-up. However, the cost of the intervention, which was approximately 50 cents per patient and may well be lower in health care systems using existing outreach resources and personnel, may be a worthwhile investment to achieve adherence improvements and pandemic safety improvements at the population level. Finally, the KP sites, and the KPNC site, in particular, made up a large proportion of study participants; this may impact generalizability to other types of health care delivery systems.

Despite limitations, this study has multiple strengths. The pragmatic, randomized study design in a real-world health care setting allowed for control of common measured and unmeasured confounders, including financial incentives for MOP use, baseline adherence levels, or other baseline patient characteristics which allows for an interpretation about true causality. The evidence-based outreach involving patient members to identify key barriers and needs as a means to encourage makes this a unique, patient-centered intervention. The large size and diverse nature of the study population from three health care systems make this study generalizable. Furthermore, restricting the outreach intervention to simple, low cost, easily replicated approaches that are commonly used in similar health care settings makes the intervention approach easier to disseminate even at relatively low levels of impact.

This modest improvement in MOP use and improved adherence to metformin indicate that well-designed, sustainable encouragement interventions using outreach materials delivered in a range of modalities may be a cost-effective tool for increasing awareness of MOP use. Our findings should be confirmed by other randomized trials and additional health care system-level interventions. Well-designed outreach efforts should be explored to further enhance our understanding of the barriers and facilitators to optimal medication usage in diabetes patients, especially in minority groups.

\section{CONCLUSION}

This pragmatic, randomized trial showed that simple, patient-centered outreach to encourage MOP modestly improved its use, improved adherence to a key class of diabetes medications, and led to improvements among White and Asian race groups. Clinicians and health systems should consider such sustainable interventions to actively promote and encourage MOP use among diabetes patients and other groups with chronic illness who would benefit from improved medication adherence.

Acknowledgments: We would like to acknowledge the contributions of Timothy Frankland from KP Hawaii to the project.

Corresponding Author: Julie A. Schmittdiel, PhD; Division of Research, Kaiser Permanente Northern California, Oakland, CA, 94612, USA (e-mail: Julie.A.Schmittdiel@kp.org).

Funding This study was funded by NIDDK grant number 1R18DK104249-01A1. Drs. Schmittdiel, Karter, and Wharam also received support from the Health Delivery Systems Center for Diabetes Translational Research (P3O DK092924). Dr. Connie Trinacty was affiliated with Kaiser Permanente Hawai'i during the time of the study.

\section{Compliance with Ethical Standards:}

Conflict of Interest: J. Frank Wharam, Wendy T. Dyer, and Dennis Ross-Degnan report receiving grants from NIDDK, during the conduct of the study. Bharathi Ramachandran, Connie M. Trinacty, O Kenrik Duru, Romain S. Neugebauer, Andrew J. Karter, Susan D. Brown, Cassondra J. Marshall, Deanne Wiley, and Julie A. Schmittdiel have nothing to disclose.

\section{REFERENCES}

1. Centers for Disease Control and Prevention (CDC). About Diabetes. https://www.cdc.gov/diabetes/basics/diabetes.html. Accessed March 17, 2020.

2. American Diabetes Association (ADA). Statistics About Diabetes. http:// diabetes.org/diabetes-basics/statistics/. Accessed October 1, 2019.

3. Lin, J., Thompson, T.J., Cheng, Y.J. et al. Projection of the future diabetes burden in the United States through 2060. Popul Health Metrics 16, 9 (2018). https://doi.org/10.1186/s12963-018-0166-4 
4. Gregg EW, Hora I, Benoit SR. Resurgence in Diabetes-Related Complications. JAMA. 2019;321(19):1867-1868. doi:https://doi.org/10.1001/ jama.2019.3471

5. Centers for Disease Control and Prevention (CDC). https://www.cdc.gov/ media/releases/2014/p0416-diabetes-complications.html. Accessed October 1, 2019.

6. Polonsky WH, Henry RR. Poor medication adherence in type 2 diabetes: recognizing the scope of the problem and its key contributors. Patient Prefer Adher 2016; 10: 1299-1307.

7. Ho PM, Rumsfeld JS, Masoudi FA, et al. Effect of medication nonadherence on hospitalization and mortality among patients with diabetes mellitus. Arch Intern Med 2006;166(17): 1836-1841.

8. Lau DT, Nau DP. Oral antihyperglycemic medication nonadherence and subsequent hospitalization among individuals with type 2 diabetes. Diabetes Care 2004;27(9):2149-2153.

9. Sokol MC, McGuigan KA, Verbrugge RR, Epstein RS. Impact of medication adherence on hospitalization risk and healthcare cost. Med Care 2005;43(6):521-530.

10. Asche $\mathbf{C}$, LaFleur $\mathbf{J}$, Conner C. A review of diabetes treatment adherence and the association with clinical and economic outcomes. Clin Ther. 2011;33(1):74-109

11. DiMatteo MR. Variations in patients' adherence to medical recommendations: a quantitative review of 50 years of research. Med Care 2004;42(3):200-209.

12. Feldman R, Bacher M, Campbell N, Drover A, Chockalingam A Adherence to pharmacologic management of hypertension. Can J Public Health 1998;89(5):I16-18.

13. Avorn J, Monette J, Lacour A, et al. Persistence of use of lipid-lowering medications: a cross-national study. JAMA.1998;279(18):1458-1462.

14. Heisler M, Faul JD, Hayward RA, Langa KM, Blaum C, Weir D Mechanisms for racial and ethnic disparities in glycemic control in middle-aged and older Americans in the health and retirement study. Arch Intern Med 2007;167(17):1853-60.

15. Trinacty CM, Adams AS, Soumerai SB, et al. Racial differences in longterm adherence to oral antidiabetic drug therapy: a longitudinal cohort study. BMC Health Serv Res 2009;9:24

16. Shenolikar RA, Balkrishnan R, Camacho FT, Whitmire JT, Anderson RT. Race and medication adherence in Medicaid enrollees with type-2 diabetes. J Natl Med Assoc 2006;98(7):1071-7

17. Tseng CW, Tierney EF, Gerzoff RB, et al Race/ethnicity and economic differences in cost-related medication underuse among insured adults with diabetes: the Translating Research Into Action for Diabetes Study. Diabetes Care 2008;31(2):261-6.

18. Peeters B, Van Tongelen I, Boussery $\mathbf{K}$, Mehuys E, Remon JP, Willems S. Factors associated with medication adherence to oral hypoglycaemic agents in different ethnic groups suffering from type 2 diabetes: a systematic literature review and suggestions for further research. Diabet Med 2011;28(3):262-75

19. Duru OK, Gerzoff RB, Selby JV, et al. Identifying risk factors for racial disparities in diabetes outcomes: the translating research into action for diabetes study. Med Care 2009;47(6):700-6.

20. van Dulmen S, Sluijs E, van Dijk $L$, de Ridder D, Heerdink R, Bensing J. Patient adherence to medical treatment: a review of reviews. BMC Health Serv Res 2007;7:55.

21. McDonald HP, Garg AX, Haynes RB. Interventions to enhance patient adherence to medication prescriptions: scientific review. JAMA 2002;288(22):2868-2879.

22. Lee JK, Grace KA, Taylor AJ. Effect of a pharmacy care program on medication adherence and persistence, blood pressure, and low-density lipoprotein cholesterol: a randomized controlled trial. JAMA 2006;296(21):2563-71.

23. Duru OKK, Schmittdiel J, Dyer W, et al. Mail order pharmacy use and adherence to diabetes-related medications. Am J Manag Care 2010;16(1):33-40

24. Schmittdiel J, Karter A, Dyer W, et al. The comparative effectiveness of mail order pharmacy vs. local pharmacy use on LDL-C control in new statin users. J Gen Intern Med 2011; 1396-402.

25. Sharma KP, Taylor TN. Pharmacy effect on adherence to antidiabetic medications. Med Care 2012;50:685-691.
26. Zhang L, Zakharyan A, Stockl KM, Harada ASM, Curtis BS, Solow BK Mail-order pharmacy use and medication adherence among Medicare Part D beneficiaries with diabetes. J Med Econ, 2011;14(5):562-567.

27. Devine $\mathbf{S}$, Vlahiotis A, Sundar $\mathbf{H}$. A comparison of diabetes medication adherence and healthcare costs in patients using mail order pharmacy and retail pharmacy. J Med Econ, 2010;(2):203-2011.

28. Fernandez E, McDaniel JA, Carroll NV. Examination of the link between medication adherence and use of mail-order pharmacies in chronic disease status. J Manag Care Spec Pharm 2016;22(11):1247-59.

29. Johnsrud M, Lawsen KA, Shepherd MD. Comparison of mail order with community pharmacy in plan sponsor cost and member cost in two large pharmacy benefit plans. J Manag Care Pharm, 2007; 13(2):122-34.

30. Carroll NV, Brusilovsky I, York B, Oscar R. Comparison of costs of community and mail service pharmacy. JAM Pharm Assoc 2003;45(3):336-343.

31. Centers for Disease Control and Prevention (CDC). Coronavirus Disease 2019. https://www.cdc.gov/coronavirus/2019-ncov/specific-groups/ high-risk-complications.html. Accessed March 12, 2020.

32. Karter AJ, Parker MM, Duru KO, et al. Impact of a pharmacy benefit change on new use of mail order pharmacy among diabetes patients: The Diabetes Study of Northern California (DISTANCE). Health Serv Res 2015;50(2):537-59.

33. Schmittdiel JA, Marshall CJ,Wiley D, et al. Opportunities to Encourage Mail Order Pharmacy Use in Diabetes-A Qualitative Study. Diabetes 2018, 67 (Supplement 1).

34. Marsha A. Raebel, Schmittdiel JA, et al. Standardizing Terminology and Definitions of Medication Adherence and Persistence in Research employing Electronic Databases. Med Care. 2013; 51(8 0 3): S11-S21.

35. Schmittdiel JA, Adams SR, Goler N, et al. The impact of telephonic wellness coaching on weight loss: A "Natural Experiments for Translation in Diabetes (NEXT-D)” study. Obesity (Silver Spring) 2017;25(2):352-356.

36. Schwab, Phil, et al. A Retrospective Database Study Comparing Diabetes-Related Medication Adherence and Health Outcomes for MailOrder Versus Community Pharmacy. J Manag Care Specialty Pharm 2019; 25(3):332-340.

37. Adams AS, Uratsu C, Dyer W, et al. Health system factors and antihypertensive adherence in a racially and ethnically diverse cohort of new users. JAMA Intern Med 2013; 173(1):54-61.

38. Liberman JN, Wang Y, Hutchins DS, Slezak J, Shrank WH. Revealed preference for community and mail service pharmacy. J Am Pharm Assoc (2003). 2011;51(1):50-7.

39. Tamblyn R, Laprise R, Hanley JA, et al. Adverse events associated with prescription drug cost sharing among poor and elderly persons. JAMA. 2001;285(4):421-9.

40. Chernew M, Gibson TB, Yu-Isenberg K, Sokol MC, Rosen AB, Fendrick AM. Effects of increased patient cost sharing on socioeconomic disparities in health care. J Gen Intern Med 2008;23(8):1131-6.

41. Osborn CY, Cavanaugh K, Wallston KA, et al. Health literacy explains racial disparities in diabetes medication adherence. J Health Commun 2011;16 Suppl 3:268-78.

42. Lewis LM, Ogedegbe C, Ogedegbe G. Enhancing adherence of antihypertensive regimens in hypertensive African-Americans: current and future prospects. Expert Rev Cardiovasc Ther 2012;10(11):1375-80.

43. Schoenthaler A, Allegrante JP, Chaplin W, Ogedegbe G. The effect of patient-provider communication on medication adherence in hypertensive black patients: does race concordance matter? Ann Behav Med 2012;43(3):372-82.

44. Saha S, Freeman M, Toure J, Tippens KM, Weeks C, Ibrahim S. Racial and ethnic disparities in the VA health care system: a systematic review. J Gen Intern Med 2008;23(5):654-71.

45. Nichols GA, Bell TJ, Pedula KL, O'Keeffe-Rosetti M. Medical Care Costs Among Patients With Established Cardiovascular Disease. Am J Manag Care 2010;16(3):e86-93.

Publisher's Note Springer Nature remains neutral with regard to jurisdictional claims in published maps and institutional affiliations. 